\title{
РЕСТРУКТУРИЗАЦИЯ ПРОМЫШЛЕННЫХ КОМПАНИЙ: ПЛАНИРОВАНИЕ, РЕАЛИЗАЦИЯ, ОЦЕНКА ПОСЛЕДСТВИЙ
}

\author{
(C) 2021 Джема Радоин \\ аспирант кафедры Экономической теории и менеджмента \\ Московский педагогический государственный университет, Россия, Москва \\ E-mail: radouanealgur@gmail.com
}

В настоящее время промышленные компании во всех странах, и развивающихся странах в частности, испытывают новые проблемы из-за неопределенности из-за портрета Covid-19 в контексте дисбаланса между объемом производства в промышленных компаниях и объемом рыночного спроса. Это приводит к необходимости установления решений посредством теоретических и практических исследований, которые помогут промышленным компаниям справиться с текущими сложными условиями и улучшить свои показатели, которые требуют реструктуризации промышленных компаний. Таким образом, мы сталкиваемся с всеобъемлющим и специализированным исследованием, основанном на трех основных этапах: планирование, внедрение и оценка воздействия

Ключевые слова: реструктуризация, промышленные компании, планирование, реализация реструктуризации, оценка воздействия реструктуризации, реструктуризация промышленных компаний.

Данное исследование основано на том факте, что процесс реструктуризации промышленных компаний состоит из этапов: планирование, реализация и оценка воздействия. Это должно стать отправной точкой для нашего исследования, направленного на повышение эффективности любой продуманной и жизнеспособной стратегической альтернативы через процесс реструктуризации путем реализации действительно сбалансированного и устойчивого плана реструктуризации промышленности для увеличения производства и сбалансированности. Реструктуризация понимается как одно из средств гибкости, различия, качества и прогресса в макро- и микроэкономике. Используемое промышленное оборудование и машины, включая станки, устройства, электронные изделия и рабочая сила, являются разными областями производства. В то же время успешная деятельность промышленных компаний может способствовать обеспечению стабильной микро- и макроэкономической позиции [1].

В целом автор считает, что реструктуризация является стратегическим решением высшего руководства компании и направлена на повышение прибыльности компании или повышение ее совместимости с факторами окружающей среды.

Процесс реструктуризации промышленной компании предназначен для достижения некоторых или всех следующих целей:

- Максимизировать рыночную стоимость промышленной компании, определив стратегические и оперативные возможности для определения потенциальной стоимости по внутреннему и внешнему развитию, а затем выявлять и использовать возможности для оптимизации для достижения реальной стоимости компании;

- Консолидация общих политик промышленной компании посредством интеграции компаний с противоречивыми и конкурирующими интересами в рамках организованного управления или административного аппарата, что повышает эффективность;

- Сокращение расходов и затрат, путем отмены или сокращения двойных администраций по производительности, задачам и целям;

- Достижение гибкости организационных структур со скоростью реагирования на экологические переменные, окружающие промышленную компанию и доступ к соответствующему уровню децентрализации решений, а также делегирование полномочий;

- Сохранить современное технологическое развитие и необходимость использования передовых технологический. Это означает скорость выполнения задач и доступа к информации своевременно и особенно в отношении обработки данных, и преобразованных в четкую и точную информацию, и, следовательно, возможность принятия правильных решений.

На практике единого плана реструктуризации промышленных компаний нет. Мы обна- 
ружили, что каждая промышленная компания обладает характеристиками, которые требуют от нас подготовки плана реструктуризации, который соответствует наилучшей стратегической альтернативе выбранному направлению деятельности промышленной компании. На протяжении десятилетий стратегическое мышление пыталось ответить на три основных вопроса: Где мы? Куда мы хотим пойти? Как мы туда попадем? Реструктуризация промышленности фокусируется на том, как делать что-то более эффективно и какие основные процессы необходимо соблюдать. Условия неопределенности, с которыми в настоящее время сталкиваются промышленные компании, связаны с проблемой анализа и расчета внутренних и внешних факторов окружающей среды при моделировании экономического поведения промышленных компаний в рыночных условиях. В настоящее время необходимы качественно новые программные инструменты для поддержки разрешения ситуаций неопределенности, особенно диалоговых систем, в зависимости от типов промышленных компаний и решений, которые необходимо решать [2].

Среди основных концепций стратегии реструктуризации:

$\diamond$ Стратегия децентрализованной реструктуризации, которая, по мнению автора, представляет собой процесс передачи источника принятия решений на уровень филиальных центров и подразделений центральной администрации, то есть имеется в виду оперативные решения и некоторые стратегические решения, не являющиеся ответственностью центральной администрации. Для проведения реструктуризации компании должен быть доступен алгоритм формирования стратегии децентрализации:

- Хорошая оценка перспектив подразделений компании с точки зрения выбранной стратегической альтернативы;

- Приоритезация экономического воздействия при разработке организационной структуры;

Определение обязанностей, распределенных между филиалами и подразделениями.

$\diamond$ Интеграционная стратегия реструктуризации. Автор считает, что это процесс объединения производственных единиц, активов или частей промышленных компаний с общими целями и организации единого промышленного комплекса для получения синергетического эффекта. Стратегия интегративной реструктуриза- ции требует этого алгоритма:

- Анализ и оценка целей и интеграции и ее влияния на экономическую эффективность;

- Выбор типа интеграции, поиск и оценка компаний, номинированных на объединение;

- Выбор и оценка средств реализации интеграционной стратегии реструктуризации;

- Расчет потенциальной экономической эффективности реализации интеграционной стратегии реструктуризации;

- Мотивация персонала и координация действий [3].

$\diamond$ Стратегия трансформационной реструктуризации. Автор понимает, что это процесс трансформации структуры или некоторых структур, принадлежащих производственным единицам промышленной компании, с сохранением централизации принятия решений и интеграции производственных мощностей и активов с другими промышленными компаниями с общими целями. Стратегия трансформационной реструктуризации требует следующего алгоритма:

- Оцените эффективность организационной структуры и экономическую эффективность хозяйственной деятельности компании;

- Современный дизайн организационной структуры и (или) бизнес-процессов;

- Наличие новой финансовой структуры и дизайна информационной системы бухгалтерского учета;

- Планирование и реализация показателей эффективности отделов и филиалов, связанных с переводом;

- Выбор и внедрение эффективной модели управления экономикой и размещение центров стоимости.

Но стратегические концепции реструктуризации компании тесно связаны с причинами реструктуризации. Внешние причины реструктуризации связаны с рыночными изменениями в управлении, снижением цен на готовую продукцию, ростом цен на сырье для производства и улучшением качества продукции и аналогичных товаров. И внутренние причины, такие как приобретения, проблемы и споры между совладельцами или банкротство промышленной компании. Но в настоящее время одной из наиболее частых причин реструктуризации компаний является ухудшение рабочих мест промышленных компаний из-за вируса Covid-19 и глобального экономического неравенства. Наше исследова- 
ние во многом связано с улучшением финансового восстановления компании для преодоления этого кризиса. Для этого при оценке эффективности процесса реструктуризации компании, в разгар кризиса Covid-19 необходимо преобразовать ожидаемые и расчетные показатели при выборе лучшей стратегической альтернативы в положительные, помимо постоянства коэффициента ликвидности и соотношение его оборотных средств с его нормативной стоимостью.

Это включает в себя постоянное наблюдение за этапами реструктуризации, оценку результатов деятельности и изучение новых рыночных условий для управления во время и после реструктуризации. Поддержка со стороны государства необходима в этот трудный период, чтобы достичь четкого видения перспектив формирования ориентированной на экспорт отрасли на глобальном уровне, снятия ограничений и облегчения экспорта при сохранении аудита и административного контроля, инвестировании в исследования и деятельность по развитию и помощь в предоставлении возможностей для улучшения продукта. Последние факторы способствуют росту и скорости. Политика спроса тесно связана с рынком, а также с защитой внутреннего рынка и продвижением экспорта [4]. Таким образом, реструктуризация необходима для преобразования в современные и эффективные компании, основанные на концентрированном росте, что означает восстановление традиционных позиций компании на рынке путем выхода на новые рынки с теми же традиционными продуктами, создания новых продуктов и их вывода на традиционный рынок. Это требует повышения эффективности производства, производительности сотрудников и финансовых возможностей за счет использования методов реструктуризации и изменений в компании. На рисунке 1 показаны этапы реструктуризации промышленных компаний.

Среди основных моментов, на которые направлен процесс планирования до начала фактического осуществления процесса реструктуризации промышленных компаний, стоит выделить:

$\diamond$ Четкое и реалистичное стратегическое направление, повышение осведомленности и обучение сотрудников, владельцев и руководства с целью сосредоточения усилий на реструктуризации для будущего успеха промышленных компаний. Это достигается путем разработки стратегии, которая дает полезные рекомендации по реструктуризации компании в форме целенаправленного проектного подхода, основанного на двух предположениях о стратегическом направлении:

- Существуют правила «императивов конкурентоспособности», которым должна следовать каждая промышленная компания, чтобы не отставать от конкуренции в отрасли. Стратегии, сосредоточенные на «императивах конкурентоспособности», могут создать временное конкурентное преимущество, но эта стратегия лучше для того, чтобы догнать конкурентов и превзойти их;

- Промышленные компании, которые стремятся быть лидерами в конкуренции, должны делать больше, чем просто следовать основам, они должны быть действительно разными, поскольку у них есть «сфокусированная компания», и это позволяет им преуспевать только тогда, когда все сотрудники, владельцы и руководство знают и понимают это.

$\diamond$ Снижение негативного воздействия организационной сложности и уменьшение бес-

\begin{tabular}{|c|c|c|c|c|}
\hline & & Сравнение & & \\
\hline & \multirow{2}{*}{$\begin{array}{c}\text { Программа } \\
\text { реструктуризации } \\
\text { согласно } \\
\text { выбранной } \\
\text { стратегии }\end{array}$} & $\begin{array}{c}\text { программой } \\
\text { реструктуризаци } \\
\text { и }\end{array}$ & \multirow{2}{*}{$\begin{array}{c}\text { Оцените каждый } \\
\text { этап реализации } \\
\text { с улучшениями } \\
\text { программы } \\
\text { реструктуризаци } \\
\text { и }\end{array}$} & \\
\hline \multirow{2}{*}{$\begin{array}{c}\text { Планирование } \\
\text { процесса } \\
\text { реструктуризаци } \\
\text { и }\end{array}$} & & \multirow{2}{*}{$\begin{array}{l}\text { Осуществление } \\
\text { процесса } \\
\text { реструктуризаци } \\
\text { и }\end{array}$} & & \multirow{2}{*}{$\begin{array}{c}\text { Оценить влияние } \\
\text { процесса } \\
\text { реструктуризациг }\end{array}$} \\
\hline & & & & \\
\hline
\end{tabular}

Рисунок 1. Этапы реструктуризации промышленных компаний 
порядка. Прежде чем сосредоточиться на сотрудниках, важно разработать структуру и стратегическую позицию компании. Упрощение руководящих ролей за счет четких и эффективных процессов, включая четкие контрольные журналы, и упрощение организационных структур компании;

$\diamond$ Прежде чем определять роли и обязанности, важно иметь четкое представление об основных действиях, которые определяют проект. Определите основные компетенции, которые определяют деятельность компании. Это необходимо для усиления этой деятельности, добавляющей ценность для компании. Следует исключить другие менее важные виды деятельности, которые не добавляют ценности;

$\diamond$ Способность измерять эффективность и продуктивность путем исключения рабочих мест, которые не способствуют созданию добавленной стоимости (снижение затрат), и реалистичное распределение ролей и обязанностей для задач, которые соответствуют стратегическому направлению промышленной компании;

$\diamond$ Планирование для достижения баланса в управлении рабочей нагрузкой, где функции управления представляют собой сочетание управления и лидерства. Для поддержания правильного баланса между работой и управлением важны эти элементы: количество сотрудников, находящихся под прямым контролем, способность сотрудников выполнять свои задачи без присмотра и уровень «обслуживания» менеджера компании.

Отдельный план должен быть подготовлен в определенное и последовательное время, а также должны быть определены стандарты для измерения и мониторинга производительности во всех секторах. Среди важнейших базовых пунктов программы реструктуризации промышленных компаний:

$\diamond$ Определение целевых рынков - предложение улучшения и диверсификации продукции - меры по снижению затрат и повышению производительности - количество и определение потребностей клиентов для увеличения их доли на рынке и определение подходящих методов распределения для клиентов путем разработки плана прямого маркетинга и внедрения новейших технологических усовершенствований в электронику;

$\diamond$ Изменение сроков погашения и списание долга путем переговоров с кредиторами о гра- фике погашения долга или уступке его части, и в этой части должно быть достигнуто комплексное решение.

$\diamond$ Преобразование долга во вклад в капитал: использование этого инструмента для поддержки промышленной компании путем конвертации долгов или их части во вклад в капитал. Этот шаг может считаться в некоторой степени опасным, но он входит в число решений;

$\diamond$ Переоценка активов, балансовая стоимость которых может быть меньше реальной стоимости и может быть переоценена, чтобы поглотить и покрыть часть накопленных убытков. Предлагается провести исследование для определения законодательных поправок, необходимых для проведения переоценки активы, так как это зависит от правового и налогового законодательства государства;

$\diamond$ Улучшение организационной структуры должно обеспечить оптимальное количество подразделений, иерархию зависимости и сбалансированность процессов обновления и поддержания количественного состава сотрудников;

$\diamond$ Развитие систем управления и навыков менеджеров посредством разработки административных и организационных методов в промышленной компании путем оценки эффективности администрации и ее лидерских способностей, а также возможных корректировок, которые могут быть сделаны в этом отношении;

$\diamond$ Разработка подходящих альтернатив для изменения структуры занятости, а также обучение и обогащение запаса знаний, навыков, способностей, мотивации и здоровья работников, что способствует росту производительности труда и снижению рисков [5], поэтому в этом отношении необходимо учитывать следующие моменты:

- Повышение занятости;

- Разработка системы хозрасчета;

- Разработка структуры заработной платы и системы стимулирования;

- Разработка обучающих систем.

Затем следует фаза фактической реализации программы реструктуризации в соответствии с тем, что было запланировано, с использованием показателей оценки и измерения эффективности и приборной панели для определения отклонений от запланированных значений на первом этапе. Критический период для успешной 
реструктуризации - первые шесть недель. Все работники, владельцы и руководство должны попытаться реализовать заранее запланированную программу, в частности, посредством ролевой игры, определения положения и принятия ответственности, включая действия, цели, уровень делегирования полномочий при принятии решений и способы его измерения. На практике, в ходе реализации программы реструктуризации промышленных компаний на местах, со временем нам становится ясно, насколько точен и полон план, составленный в процессе планирования, позволяющий избежать рисков, связанных с реструктуризацией, в том числе рисков, связанных с развитием социальной ответственности компаний, современного рынка и неопределенности.

Процесс планирования и реализации реструктуризации промышленных компаний может быть трудным и сложным, но как только компания начинает его реализовывать и после того, как сотрудники адаптируются к условиям работы в новой среде, промышленная компания обычно лучше оснащена для достижения своих целей. Кроме того, необходимо следить за тем, чтобы каждое изменение производственной компании приближало ее к качеству работы, запланированной на рынке. Таким образом, производственная фирма, которая подвергается реструктуризации, соответствующим образом реагирует на изменения, повышая эффективность производства, и с течением времени фактически пропорциональна спросу и предложению на рынке. В целом, для оценки эффекта реструктуризации в промышленных компаниях потенциальная стоимость промышленной компании после реализации процесса реструктуризации берется за основу для сравнения с реальной приведенной стоимостью компании во время реализации процесса реструктуризации. А также при сравнении ее с предыдущей стоимостью компании из-за эффективности выбранной стратегической альтернативы возникает разрыв, который при реализации процесса реструктуризации в нашем исследовании называется разрывом затрат. Обычно процесс реструктуризации занимает от 2 до 5 лет, и автор считает, что этого срока достаточно, чтобы знать степень влияния процесса реструктуризации на экономическую эффективность промышленной компании.

Автор предлагает использовать следующую модель для оценки внутренней стоимости любой местной компании при оценке воздействия процесса реструктуризации при отсутствии конфликта бухгалтерского учета с основными показателями, используемыми в этой модели [7]:

Рассчитайте разрыв затрат, рассчитав расчетную величину дисконтированного денежного потока в будущем (сумма дополнительной прибыли от реструктуризации за определенный период времени, дополнительных инвестиций в реструктуризацию. Высокая ставка налога на текущий период и коэффициент изменения производственных затрат). В нашем исследовании разрыв в стоимости - это разница между ожидаемой будущей стоимостью потенциальных денежных потоков после реструктуризации и приведенной стоимостью денежных потоков во время проведения реструктуризации. Для определения стоимости компании автор считает определение текущей стоимости текущих свободных денежных потоков. Естественно, нам нужно найти денежные потоки, прежде чем мы сможем дисконтировать их до приведенной стоимости.

Свободный денежный поток от операционной деятельности - это денежные средства, полученные от операционной деятельности, которые относятся ко всем поставщикам капитала в структуре капитала компании. Сюда входят поставщики долговых обязательств, а также акционерный капитал. Разница в оборотном капитале рассчитывается путем вычитания налогов, корректировки ставки налога, вычитания прибыли до процентов, затем добавления амортизации и исключения капитальных затрат за вычетом изменений в оборотном капитале и вычитанием изменений в других активах.

Свободный денежный поток компании, рассчитанный, например, для отражения общей способности компании генерировать денежные средства до вычета процентных расходов, связанных с долгом и неденежными статьями. После вычисления этого числа мы можем вычислить другие необходимые показатели, такие как скорость роста. (См. Использование Портера 5 для анализа запасов) Рассчитайте скорость роста.

Темпы роста трудно предсказать, и они могут существенно повлиять на итоговую стоимость компании. Один из способов их рассчитать - это умножить доход на инвестированный капитал на коэффициент удержания. Любое удержание - 
это процент от прибыли, удерживаемой внутри компании, которая не выплачивается в качестве дивидендов.

Метод оценки основан на операционных денежных потоках после вычета капитальных затрат, которые представляют собой затраты на поддержание базы активов. Этот денежный поток берется до выплаты процентов держателям долга для оценки общей суммы компании. Например, учет запасов повысит акционерную стоимость. Ставка дисконтирования необходима для дисконтирования любого денежного потока, и в этом случае стоимость финансирования проектов ложится на компанию. В качестве ставки дисконтирования используется средневзвешенная стоимость капитала. Затем свободный денежный поток от операционной деятельности вычитается по процентной ставке с использованием трех возможных сценариев роста: рост, без изменения темпов роста и без роста.
Если вы хотите оценить собственный капитал компании, вычтите рыночную стоимость долга компании. Непрерывный рост в более зрелой компании может оказаться более уместным включить в расчет устойчивых темпов роста. Для расчета стоимости необходимо взять значение консолидированной денежной разницы за следующий период и дисконтировать до средневзвешенной стоимости капитала за вычетом долгосрочных постоянных темпов роста.

Следовательно, корректировки вносятся в программу реструктуризации каждый раз, когда обнаруживаются слабые места после оценки воздействия процесса реструктуризации, путем подготовки всеобъемлющего отчета о том, что было реализовано с момента последней поддержки программы реструктуризации, с целью решения проблемы реализации процесса реструктуризации до конца.

\section{Библиографический список}

1. Рябцев А.В. Основные Тенденции Реструктуризации Предприятий Отечественного Автомобилестроения, Экономика: проблемы, решения и перспективы, 2015. С. 107;

2. Радионова С.П. Формирование финансового механизма развития предприятий в условиях адаптации российской экономики к новому технологическому укладу, National Interests: Priorities and Security. 2017. C. 1492;

3. Кипень Д. В. Формирование и развитие механизма адаптивного управления на предприятиях легкой промышленности (на примере эволюционно-интегрированной организации) [ДИССЕРТАЦИЯ на соискание ученой степени кандидата экономических наук]. Кострома - 2017. С.63;

4. Чан T.Ч, Хошгияфех Р.М. Стратегия формирования автомобильной промышленности в развивающихся странах, «Экономика и управление», Известия МГТУ «МАМИ» № 4(22), 2014, С. 45;

5. Кривошеева-Медянцева Д.Д. Механизмы, Мотивы и стимулы экономического поведения в контексте институциональных изменений [08.00.01 - Экономическая теория.Диссертация на соискание ученой степени кандидата экономических наук]. Ростов-на-Дону, 2020, С.22;

6. Ситенко Д.Д. «Проблеми економіки»: Концептуальні аспекти дослідження сутності корпоративної реструктуризації № 1, Україна, 2015. С. 239;

7. Решетняк Е.И., Давыдов Д. Ю. Теоретические аспекты оценки рыночной стоимости предприятия в процессе его реструктуризации. БІЗНЕСІНФОРМ № 1 ’2017. С. 321. 